\title{
قضيَّة الطّبع والتكلّف في التراث النقدي
}

\section{د. إسماعيل حسين فتاتيت}

\section{كلية التربية - جامعة مصراتة}

الحمد لله رب العالمين، والصلاة والسلام على أشرف الأنبياء والمرسلين، سيدنا محمد

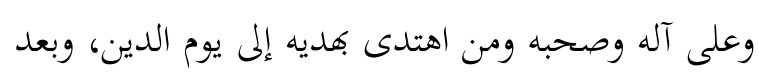

فتعدُّ قضية الطبع والتكلف من القضايا التي شغلت بال النقاد القدامى كثيرا، حتى إننا

نكاد بخزم أنَّه لا يكاد يخلو كتاب في النقد الأدبي منها، ولا ناقد إلا وأدلى بدلوه فيها. فقد بـد

حاول هؤلاء النقاد إيجاد مقياس لنقد الشعر فأطلقوا صفة المطبوع على من جاء بشعر سهل خال من التثقيف والصنعة، وصفة المتكلف على من كان شعره غير ذلك. وما كان اهتمام

النقاد بهذا المقياس إلاًّ من أجل استخدامه كوسيلة من وسائل المفاضلة بين الشعراء.

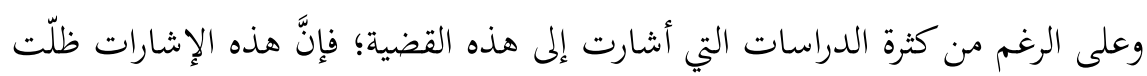
متناثرة موجزة لمُ تُعط حقها من العناية والتمحيص، إذ لا توجد دراسة جادة مستقلة متكاملة

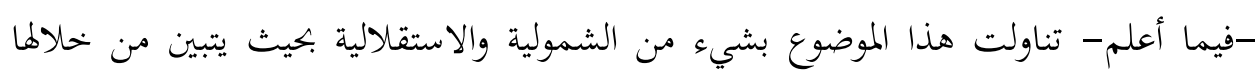

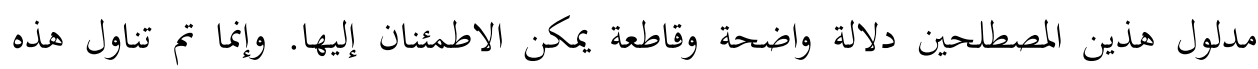
القضية في ثنايا مؤلفاهمم، فكان تعرضهم لها من خلال حكمةم على الشاعر وتقييمهم لشعره. وعبر هذا التقييم حاولوا تصنيف الشعراء إلى مطبوعين ومتكلفين، أو شاعر مطبوع وآخر متكلف. وعبر هذه الدراسة، يحاول الباحث الإجابة على العديد من الأسئلة التي يمكن أن تُطرح

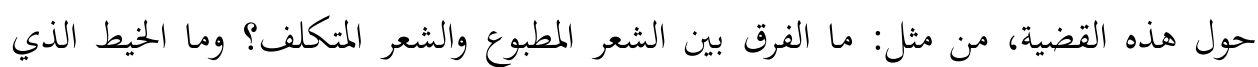

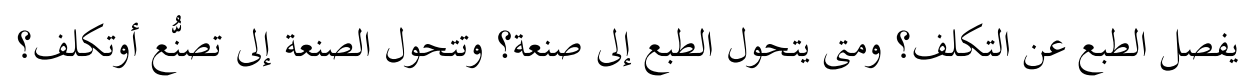


وعليه فإنَّ الأمر يتطلَّب أنْ يقوم الباحث بدراسة استقرائية للعديد من آراء قدامى النقاد، يسعى من خلالها إلى الإحاطة ـ قدر المستطاع ـ بنشاطهم النقدي المتضمن لهذه القضية. وعلى ضوء هذه الدراسة يتَّ تقسيم البحث إلى ثلاثة مطالب على النحو الآتي:

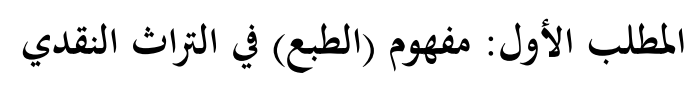

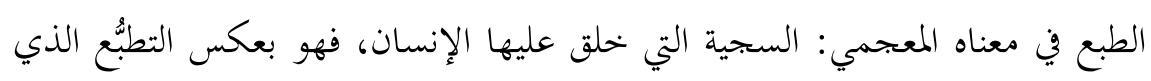
يكتسبه اكتسابا، جاء في لسان العرب (( الطبع والطبيعة: الخليقة والسجية التي جبل عليها الإنسان ))(1). وجاء في الصحاح: (( الطبع: السجية التي جبل عليها الإنسان، وهو في الأصل

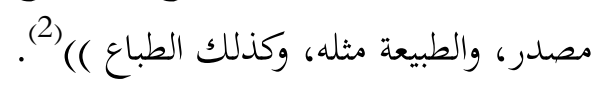
وقد استعمل العرب هذا المصطلح بحازا فقالوا: هو مطبوع على الكرم، وأيضا قالوا: هذا وإنا كلام عليه طبائع الفصاحة).

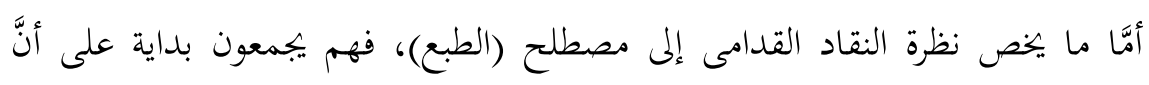
الشاعر المطبوع هو الذي يستطيع قول الشعر على السجية دون إعمال الفكر أو تكدير الفؤاد.

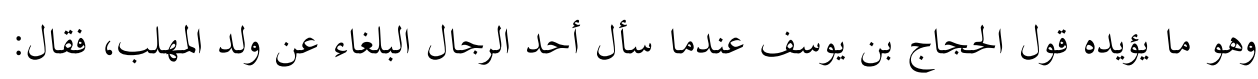

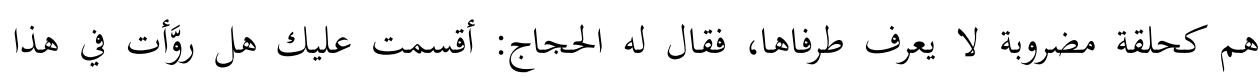

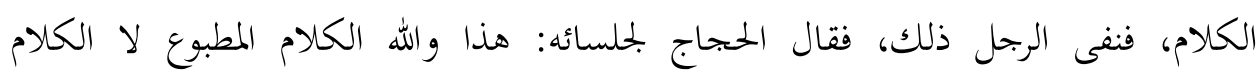
المصنوع (4)

1- ابن منظور، جمال الدين محمد بن مكرم، لسان العرب، دار صادر بيروت، ط4، 2005م، مادة: "ط،

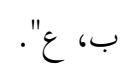

2- الجوهري، إسماعيل بن حماد، الصحاح تاج اللغة وصحاح العربية، تح: أحمد عبد الغفور عطار، دار العلم

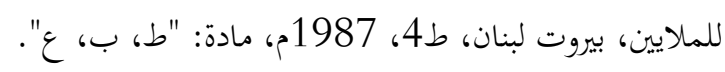

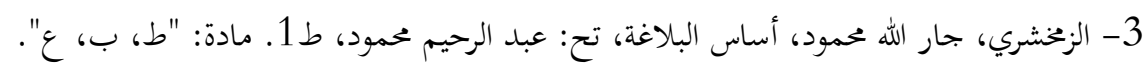

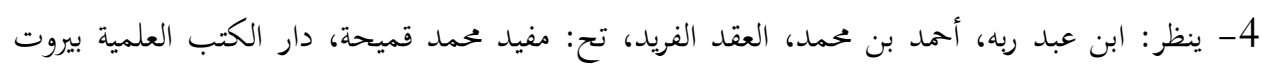
لبنان، ط3، 1987م، 330/1. 
تم إنَّ هؤلاء النقاد يتفاوتون في النظر إلى هذا الشعر المطبوع، فبعضهم يراه كيفما جاء

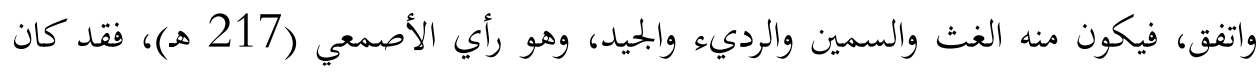

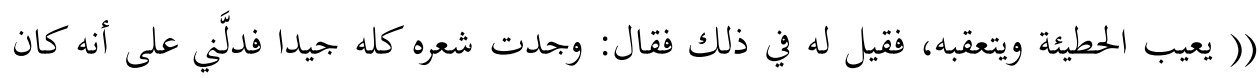
يصنعه، وليس هكذا الشاعر المطبوع؛ إنما الشاعر المطبوع الذي يرمي بالكام على على عواهنه:

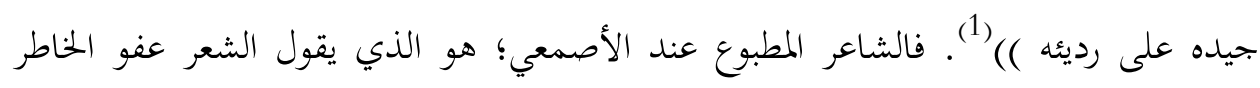

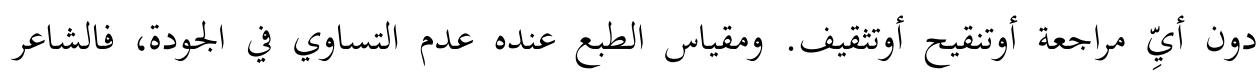
المطبوع هو الذي يكون في شعره الرديء والجحيد. فهذا التفاوت في الشعر هو علامة الطبع المائزة

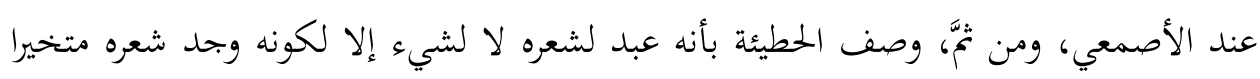
منتخبا.

وقريبا من هذا المفهوم؛ جاء مفهوم الطبع عند الجاحظ (255هـ)، وهو ما نستشفه من حديثه عن عبيد الشعر الذين يصفهم بأغم يغتصبون الألفاظ ويلتمسون قهر الكلام. وهم في رأيه أصحاب صنعة وتكلف، وليسوا كالشعراء المطبوعين الذين تتدفق عليهم الألفاظ والمعاني بيسر وسهولة فيقولون الشعر ارتجالا دونما إجهاد فكر، يقول: (( لولا أن الشعر قد كان إنه استعبدهم واستفرغ بجهودهم حتى أدخلهم في باب التكلف وأصحاب الصنعة ومن يلتمس قهر الكلام واغتصاب الألفاظ؛ لذهبوا مذهب المطبوعين الذين تأتيهم المعاني سهوا ورهوا وتنثال عليهم الألفاظ انثيالا () (2). فالشاعر المطبوع • عند الجاحظ ـ هو الذي يملك أن يقول الشعر متى هيَّأت نفسه لذلك، دون قهر للألفاظ أو إجهاد للفكر. وحدا حدو الأصمعي والجاحظ؛ أبو هلال العسكري (395 هـ)، فالطبع عنده قول

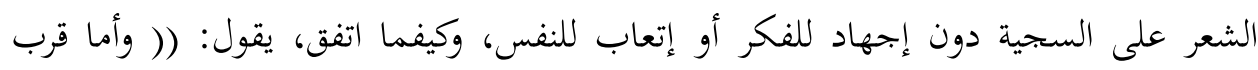

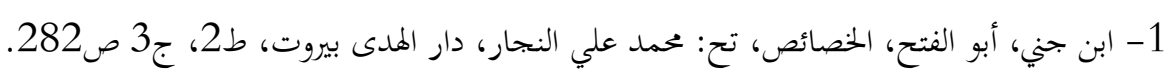

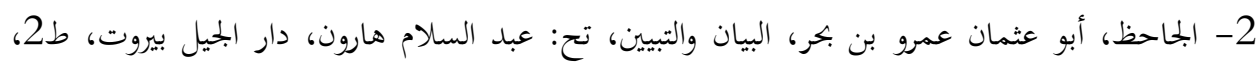


المأخذ، فهو أن تأخذ عفو الخاطر، وتتناول صفو الهاجس، ولا تكد فكرك، ولا تتعب نفسك،

وهذه صفة المطبوع ()) (1)

ويقول ضاربا أمثلة على الشعر المطبوع، (( ومن السهل المختار الجيد المطبوع، قول الآخر:

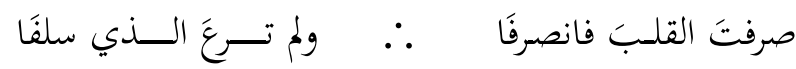

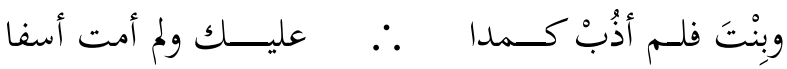

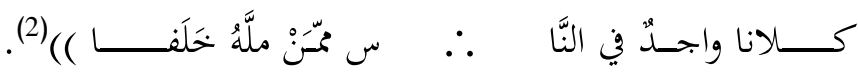

فالشاعر المطبوع عند هؤلاء هو الذي لا يجد كبير عناء في قرضه للشعر. والشعر المطبوع عندهم هو الذي يقال لأول وهلة دون معاودة أو تروّ كيفما جاء. ومن النقاد القدامى من اشترط في الشعر المطبوع الذي يأتي عفو الخاطر؛ أنْ يكون متمتعا بشيء من الحسن وبنفحة من الجودة، بأن يبتعد به صاحبه عن حوشي الكلام وتعقيد المعاني وقلق القوافي. ويأتي على رأس هؤلاء ابن قتيبة (276هـ)، فهو يصف الشاعر المطبوع بأنَّه (( من سمح بالشعر واقتدر على القوافي وأراك في صدر بيته عجزه وفي فاتحته قافيته، وتبيّت على شعره رونق الطبع ووشي الغريزة، وإذا امتحن لم يتلعثم ولم يتزحّر )(3). فالطبع عند ابن قتيبة يعني الموهبة والغريزة، والقدرة على قول الشعر، والاقتدار على القوافي. إلآّ أننا نستشف من كلامه أيضا أن من كان على هذه الشاكلة؛ لابد أن يتصف شعره بالجودة والإحسان. ويرى ابن قتيبة أيضا أن هذا الطبع يختلف من شاعر لآخر، فبعضهم لديه طبع وسهولة في غرض المديح، والآخر في الهجاء، وآخر يسهل عليه غرض الرثاء ويصعب عليه غرض الغزل،

1- العسكري، أبو هلال، كتاب الصناعتين (الكتابة والشعر)، تح: مفيد قميحة، دار الكتب العلمية بيروت،

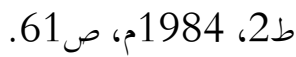

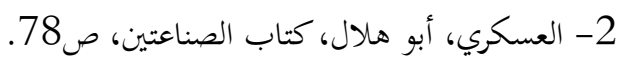

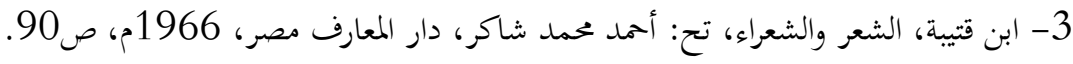


فهذا ذو الرمة أحسن الناس تشبيها، فإذا صار إلى المديح والهجاء خانه الطبع، وكان الفرزدق زير نساء، ومع ذلك لا يجيد التشبيب (1). فشعر الشاعر المطبوع عند ابن قتيبة متفاوت، فيحسن إذا وافق رغبة الشاعر وإجادته،

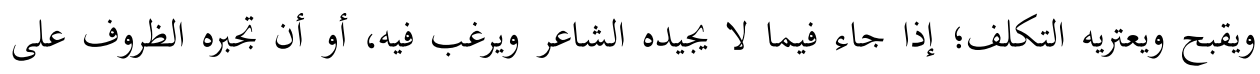

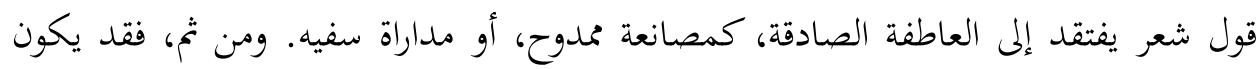

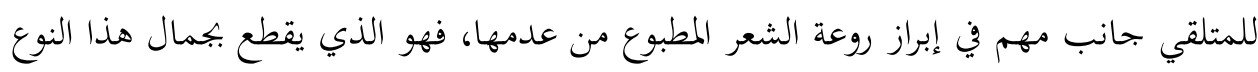

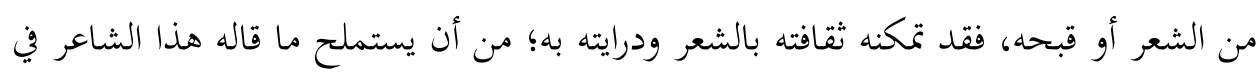
الغزل ويستقبح ما قاله في المديح. والذي أورده ابن قتيبة حول طبيعة الشعر المطبوع؛ زاد عليه الآمدي (370هـ) صفة أخرى، وهي الابتعاد عن وحشي الكلام ومعقّد المعاني، حين وصف البحتري بأنه من شعراء الطبع، فقال في معرض حديثه عن أبي تمام والبحتري، وأيهما أشعر: (( وإن كثيرا من الناس قد جعلهما طبقة وذهب إلى المساواة بينهما، وإغما لمختلفان؛ لأن البحتري أعرابي الشعر مطبوع وعلى مذهب الأوائل وما فارق عمود الشعر المعروف ...، فهو بأن يقاس بأشجع السلمي ومنصور النمري وأبي يعقوب المكفوف وأمثالهم من المطبوعين أولى. ولأن أبا تمام شديد التكلف، صاحب صنعة، ويستكره الألفاظ والمعاني، وشعره لا يشبه أشعار الأوائل )(2). فالبحتري عند الآمدي شاعر مطبوع لأنَّه لم يلجأ إلى وحشي الكالام، ولم يعقد معانيه كما كان يفعل أبو تمام الذي أدخل على شعره الصنعة بسبب مزجه العقل بالشعور، والفكر بالعاطفة(3). ومما سبق يمكن حصر آراء النقاد المتناولين لقضية الطبع في أمرين:

$$
\text { 1- ينظر : ابن قتيبة، الشعر والشعراء، ص93، } 94 .
$$

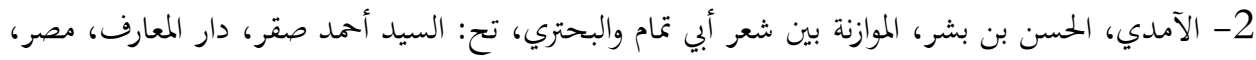

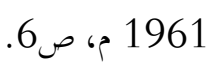

$$
\text { 3- خليف، يوسف، في الشعر العباسي، نحو منهج جديد، دار غريب القاهرة، ص96. }
$$


الأول: أنَّ مصطلح (الطبع) عند كل من الأصمعي والجاحظ والعسكري يقصد به قول

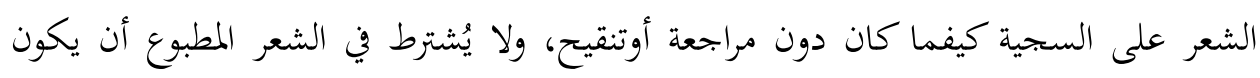

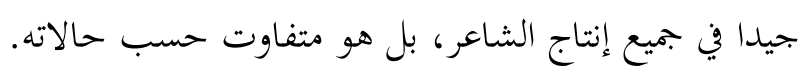

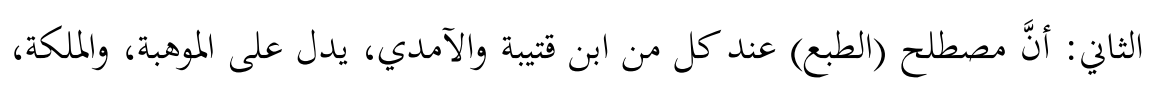

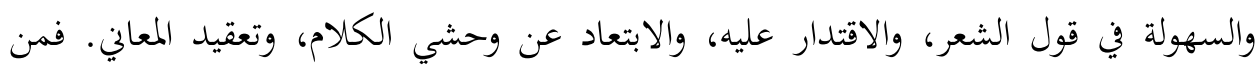
سمات الشعر المطبوع عندهما اتصافه بالمودة والجمال.

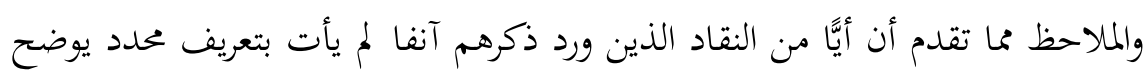

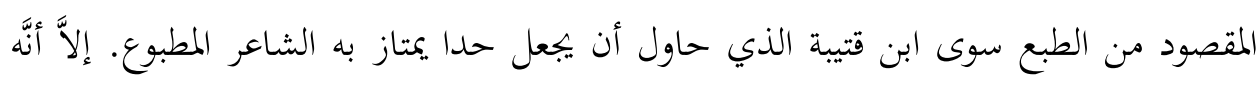

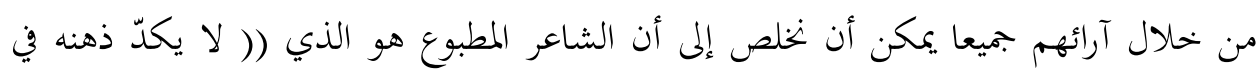
نظم القصيدة ولا يتكلف، وإنما تنساب القصيدة انسيابا من طبعه الحسن وذوقه الرقيق )( ) (1).

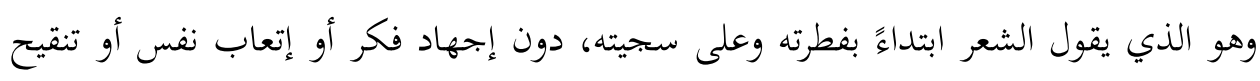

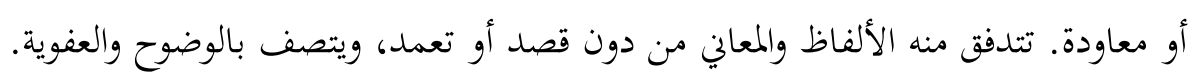

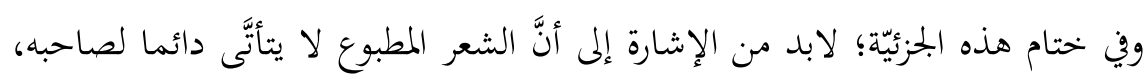

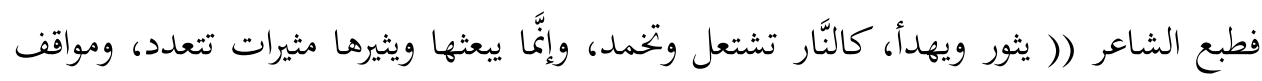

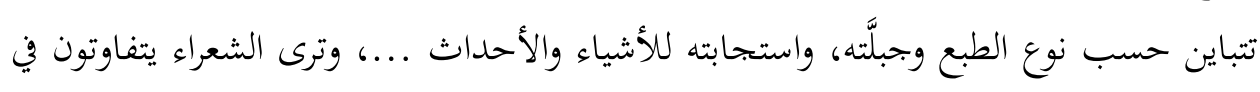

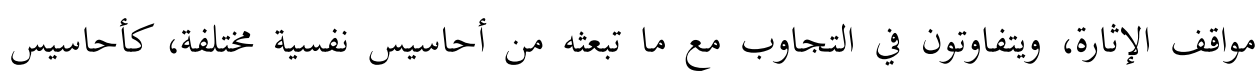

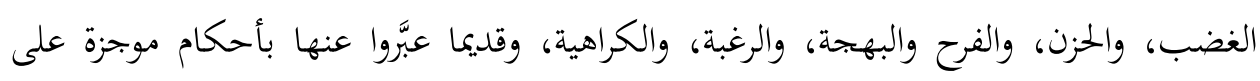

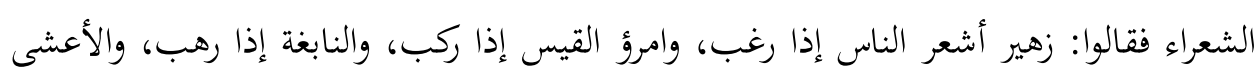

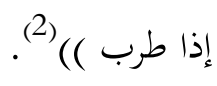

1- مطلوب، أممد، معتم النقد العربي القدي، دار الشؤون الثقافية العامة، بغداد، ط1، 1989م، .352/1

2-2 زغلول سلام، عمد، تاريخ النقد الأدبي والبلاغي حتى آخر القرن الرابع الهجري، منشأة المعارف الإسكندرية، ط3، ص57. 
فما أبدعه الشاعر من جمال؛ لا شك في أنَّه كان نتيجة لفطرة سليمة قادرة على مثل همأل

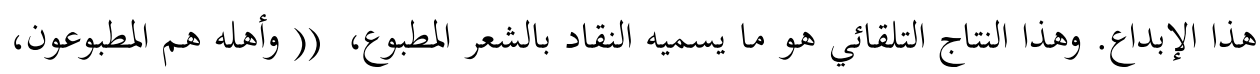
فهو يباكرهم من نفسه فلا يطاردونه ولا يطاردهم، وهو بعد ذلك قائم بذات الشعر فكلاهما

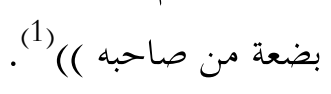

\section{المطلب الثاني: مفهوم (التكلّف) في التراث النقدي}

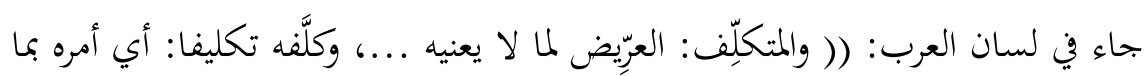
يشق عليه. وتكلفت للشيء: تجشمته على مشقة وعلى خلاف عادتك )(2) (م) ومن تم، قيل للشاعر الذي يتعرض لأشياء خارجة عن صناعة الشعر، أو الذي يجبر نفسه على أمر فيه مشقة

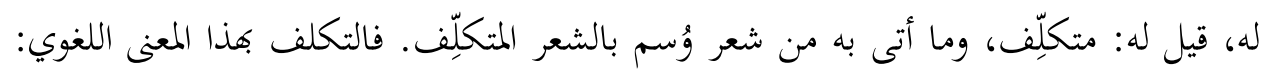

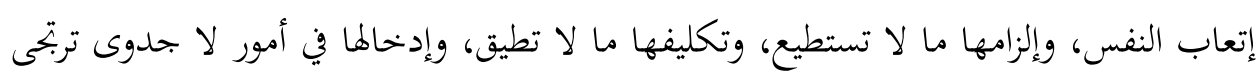
منها.

وقد ورد مصطلح (التكلّف) في كتب القدماء، ولم يمدد مدلوله تحديدا دقيقا، وإنَّا كانت نظراقم إليه نظرات متفاوتة، فقد خلط (ابن قتيبة) -مثلا- بينه وبين تثقيف الشعر وتنقيحه(أي:صناعته)، عندما قال: (( ومن الشعراء المتكلِّفِ والمطبوع، فالمتكلف هو الذي قوَّم

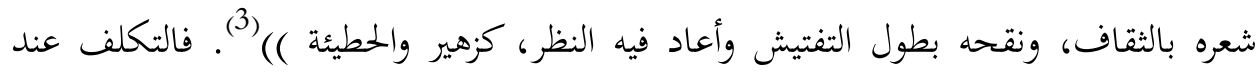

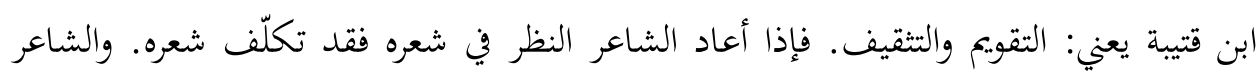

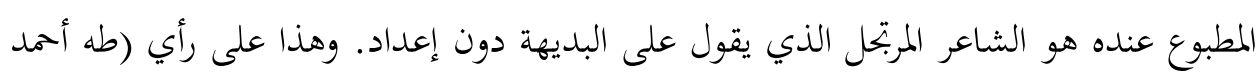
إبراهيم): (( بحاوزة للواقع والإنصاف. فالشعر صناعة ككل الصناعات تحتاج إلى مرانة وإعداد

1- الههياوي، محمد مصطفى، الطبع والصنعة في الشعر، ص71.

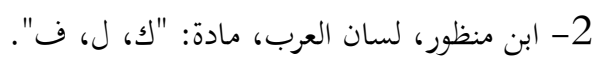

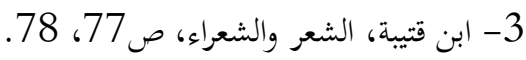




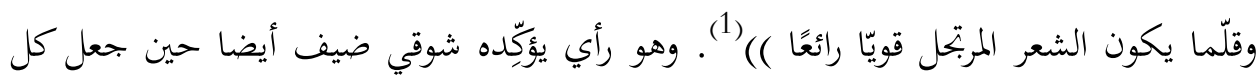

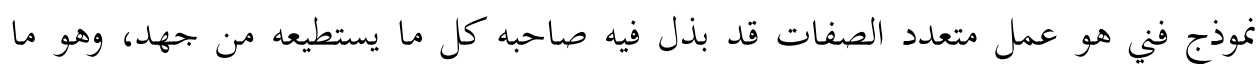

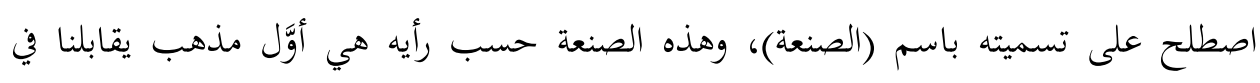

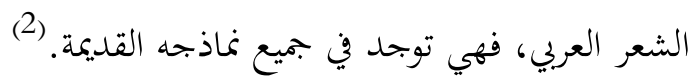

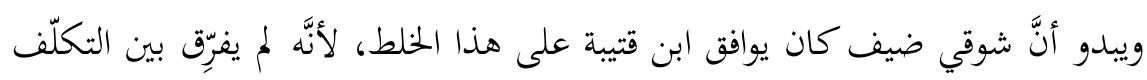

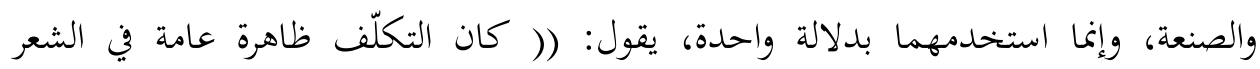

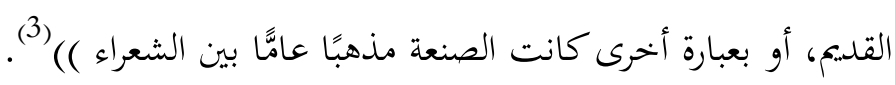

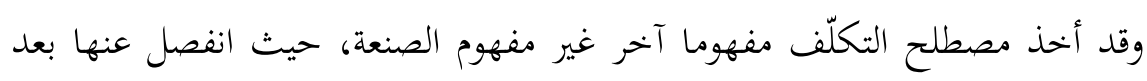

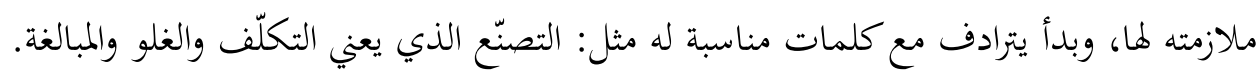

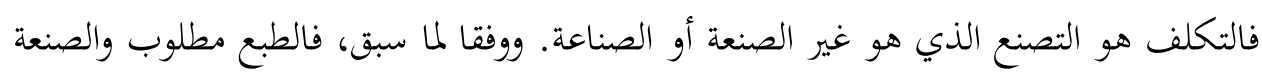

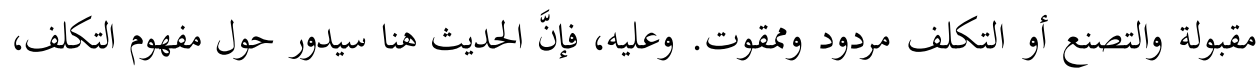
ومعرفة حدوده، والأسباب التي جعلنه مُقوتا. يقول الجرجاني صاحب الوساطة، متحدثا عن الشعراء المحدثين: ((فإن رام أحدهم

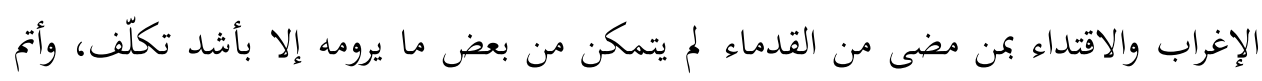

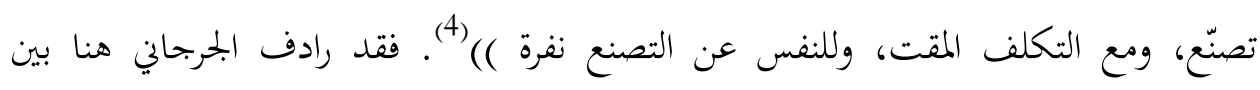
التكلّف والتصنّع. والتصنّع كما جاء في لسان العرب يعني (( تكلّف الصلاح وليس بله بله )) (5).

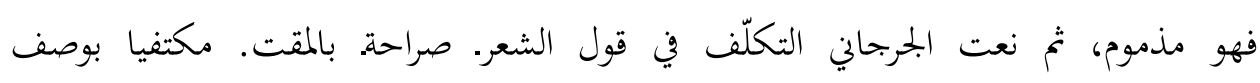
(التكلف) وصفا إجماليا دون تفصيل. 1- ينظر: إبراهيم، طه أممد، تاريخ النقد الأدبي عند العرب من العصر الجاهلي إلى القرن الرابع الهجري، دار

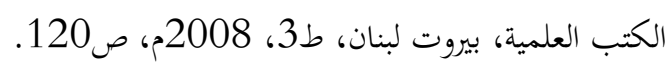

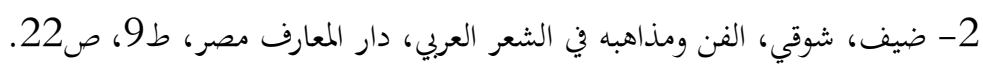

$$
\begin{aligned}
& \text { 3- المصدر السابق، ص24. }
\end{aligned}
$$

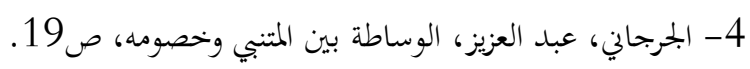

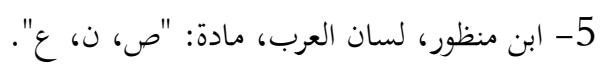


وإذا ما نظرنا في قول أبي هلال العسكري وجدنا أن معنى (التكلف) عنده قد تبلور، فجاءنا بتعريف مفصل له حيث يقول: (( التكلف طلب الشيء بصعوبة للجهل بطرايق طلبه بالسهولة، فالكلام إذا جمُع وطُلب بتعب وجهاءل، وتنولت ألفاظه من بعد فهو متكلف )( (1).

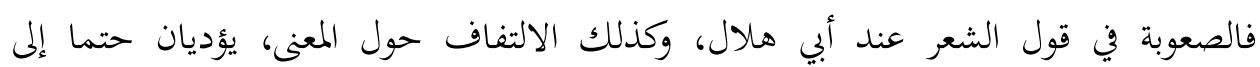
التكلّف. والشاعر الماهر عنده هو الذي يأتي بالسهل الممتنع دون مراوغة أو دوران. مما يعني أنَّ

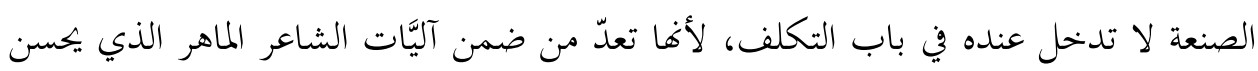

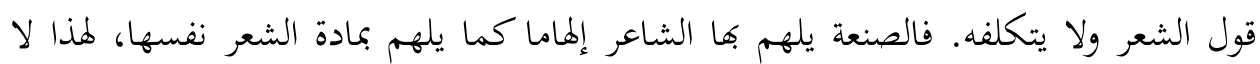
تظهر في الصنعة الموهوبة آثار التعمّل والتكلف.(2) ومن ثم، فضَّل ابن رشيق (456هـ)، البيت المصنوع بمهارة الحاذق على البيت المطبوع، يقول: (( ولسنا ندفع أن البيت إذا وقع مطبوعا في غاية الجودة، ثم وقع في معناه بيت مصنوع في فاية الحسن لم تؤثر فيه الكلفة ولا ظهر عليه

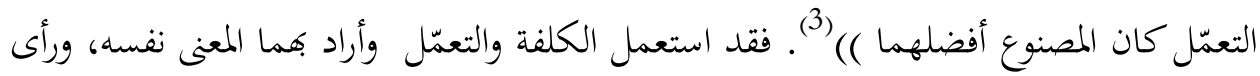

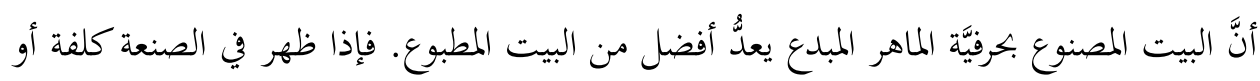
تعمّل كان المطبوع أفضل من المصنوع. أمَّا عبد القاهر الجرجاني (471 هـ)، فإنَّهَ يضمّن مصطلح (التكلف) دلالة أخرى غير دلالة العجز وادّعاء ما لا يُستطاع، فالتكلف عنده يعني: الإسراف في البديع دون الحاجة إلى إلى ذلك. وقد أشار إلى هذه الدلالة أثناء حديثه عن الجناس والسجع، وكيف أن هناك من الشعراء من يبذل كل ما لديه في سبيل إدخال ألوان البديع إلى شعره فيتكلف ذلك، يقول:

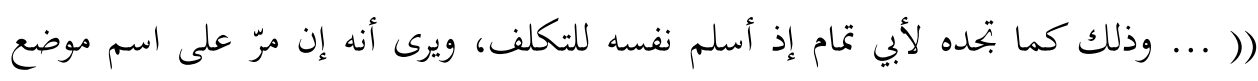

$$
\text { 1- العسكري، أبو هلال، كتاب الصناعتين، ص55. }
$$

2- ينظر: هدارة، محمد مصطفى، ابتحاهات الشعر العربي في القرن الثاني الهجري، دار العلوم العربية للطباعة

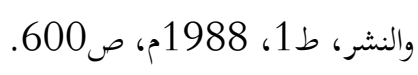

3- القيرواني، ابن رشيق، العمدة في محاسن الشعر وآدابه ونقده، تح: محمد عبد القاهر أحمد عطا، دار الكتب

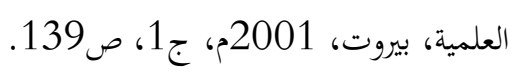


يجتاج إلى ذكره، أو يتصل بقصة يذكرها في شعره، من دون أن يشتق منه بتخيسا، أو يعمل فيه

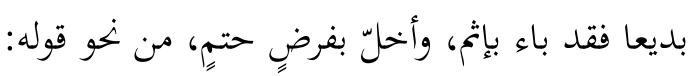

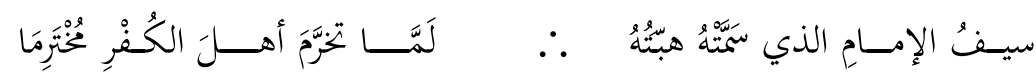

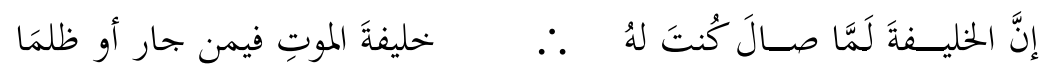

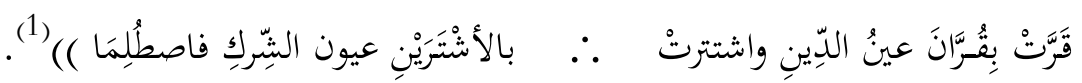

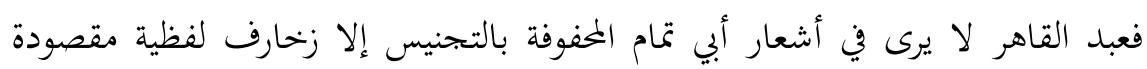

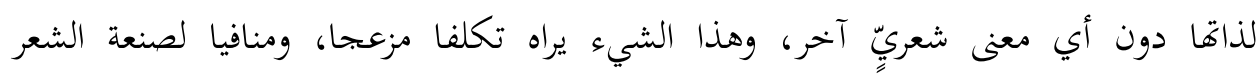

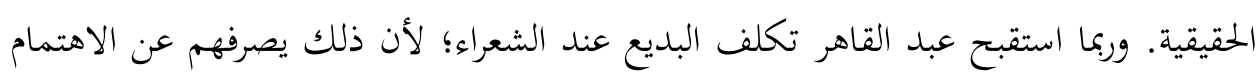
بمعانيهم التي هي محور الشعر وأصله.

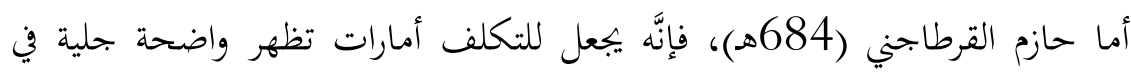

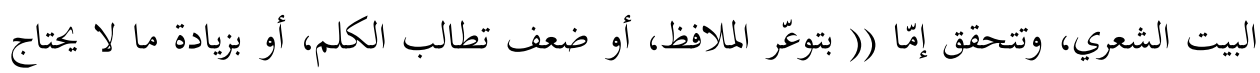

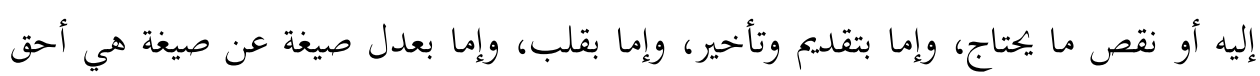

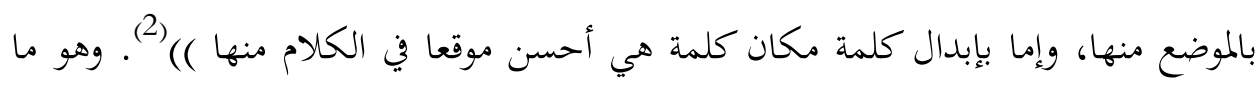

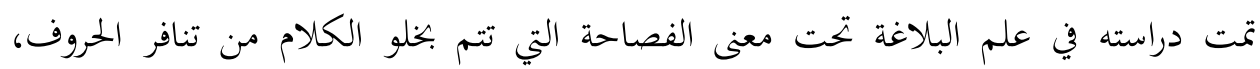

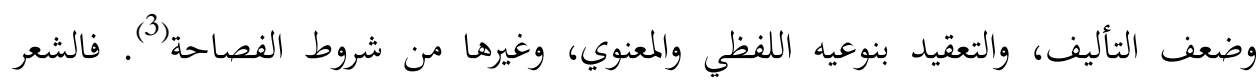
المتكلف عند حازم هو ما بني على مثل هذه الأشياء.

ومما سبق، نستنتج أن النقاد عدُّوا التكلّف عيبا يجب على على الثباء الشاعر أن يتخلص منه. وأنَّ

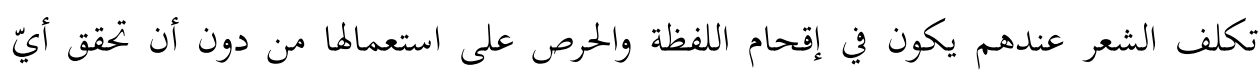

1- الجرجاني، عبد القاهر، أسرار البلاغة، تح: عممود عمد شاكر، دار المدني بجدة، ط1، 1991م، ص15. 2- القرطاجني، حازم، منهاج البلغاء وسراج الأدباء، تح: محمد الحبيب بن الخوجة، تونس، 1966م، ص.223.

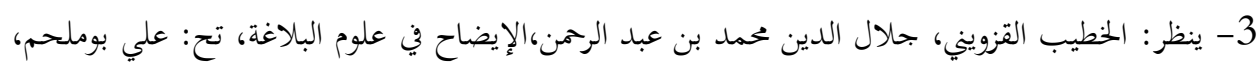

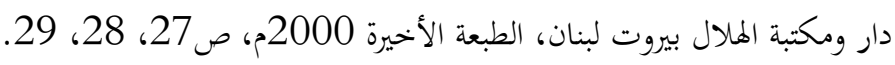


خدمة للمعنى، وفي إجهاد الفكر في طلب ما لا يلزم، ويف الكثرة المفرطة للبديع، وذكر ما لا يحتاج إليه من الزينة، وفي تنافر الحروف والكلمات، وضعف التأليف، والتعقيد بنوعيه اللفظي

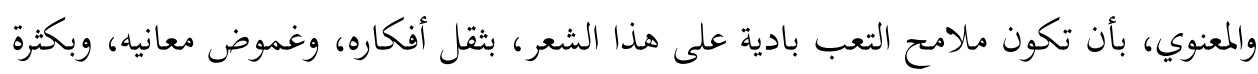

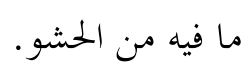
ومن خلال ما تقدم، يتضح لنا أن (التكلف) هو الوجه المقابل للطبع، والشاعر الذي يعمد إلى التكلف هو شاعر دون الشعراء. وكما حسّن النقاد الطبع وحثّوا عليه قبَّحوا في المقابل التكلف ونفَّوا منه، وحرضوا الشعراء على أن يأتوا بأشعار على السليقة دون أن يغتصبوا الألفاظ

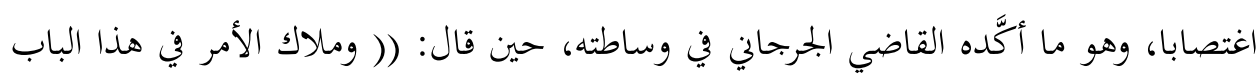
خاصة ترك التكلف، ورفض التعمّل، والاسترسال للطبع )( (1).

\section{المطلب الثالث: (الصنعة) بين الطبع والتكلف ولف الثرس}

تعني صنعة الشعر - في المعجم اللغوي ـ عمله، جاء في الصحاح: (( والصناعة حرفة

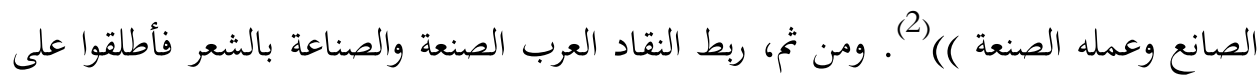

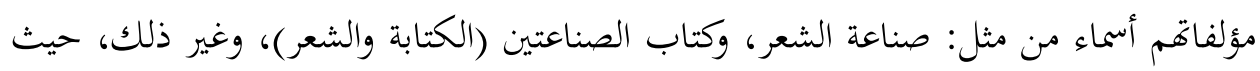
عدُّوا الشعر حرفة كباقي الحرف، يقول عمر بن الحطاب - ضي الله عنه- (( خير صناعات

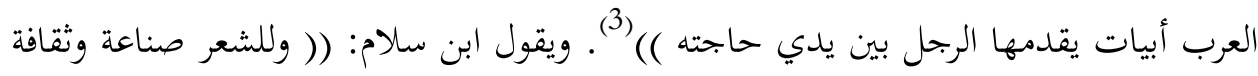
يعرفها أهل العلم كسائر أصناف العلم والصناعات، منها ما تثقفه العين، ومنها ما تثقفه الأذن،

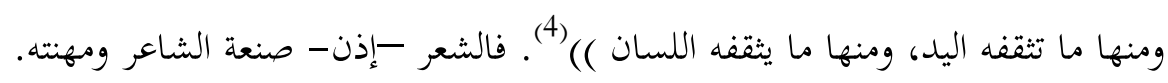
وصناعة الشعر من القضايا المهمة التي تناولها النقاد العرب القدماء وعنوا بمناقشتها، لئهاء

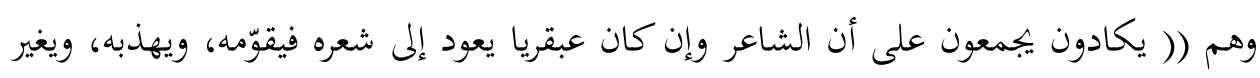

1- الجرجاني، عبد العزيز، الوساطة بين المتببي وخصومه، ص25.

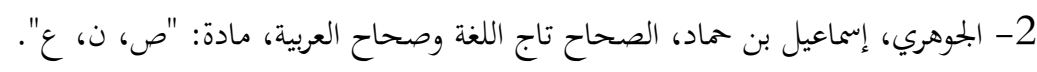

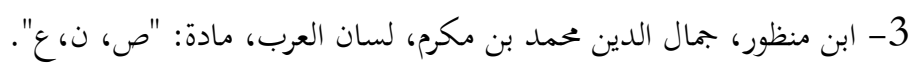

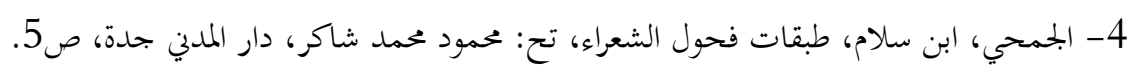


من قوافيه إذا كانت قلقة نافرة، ومن عباراته حتى تسلس وتنقاد ))(1). وذكروا أن إحكام الصنعة لابد أن يتم وفق شروط معينة، حيث حدد بعضهم ذذلك بأربعة أشياء وهي: (( جودة الآلة، وإصابة الغرض المقصود، وصحة التأليف، والانتهاء إلى تمام الصنعة من غير نقص فيها ولا زيادة عليها () (2)

ومن ثم، فإنَّ من الشعر كما يرى ابن رشيق (( مطبوع ومصنوع، فالمطبوع هو الأصل الذي وضع أولا، وعليه المدار. والمصنوع وإن وقع عليه هذا الاسم فليس متكلفا تكلف أشعار

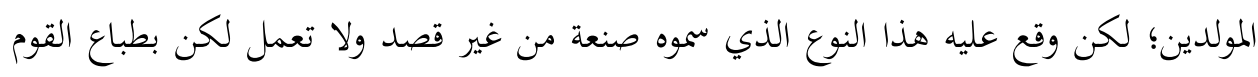
عفوا، فاستحسنوه ومالوا إليه بعض الميل بعد أن عرفوا وجه اختياره على غيره، حتى صنع زهير

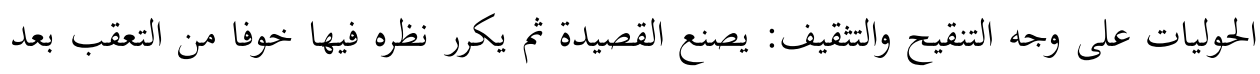
أن يكون قد فرغ من عملها في ساعة أو ليلة )( ).

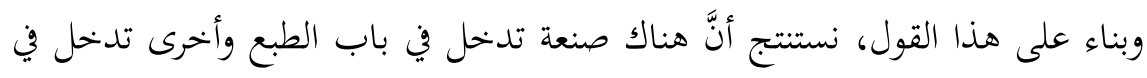
باب التكلف. والصنعة المطلوبة التي تدخل في باب الطبع؛ هي التي تكون لأجل التنقيح والتثقيف، مثل ما كان يصنع زهير في حولياته، (( فتنقيح الشعر هو تنقيته من كل ما يشينه، وتحليته بكل ما يزينه، وذلك بإعادة النظر فيه مرارا، وتفتيشه بيتا بيتا، حتى يخرج كله متخيرا

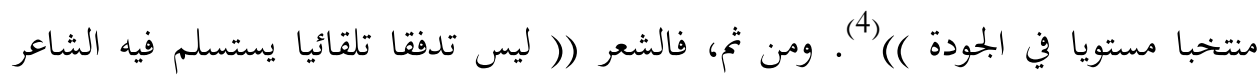
لقريحته؛ بل هو ضرب من المعاناة والمكابدة والطلب الملح، ولا يكتفي الشاعر بما أتاه لأول

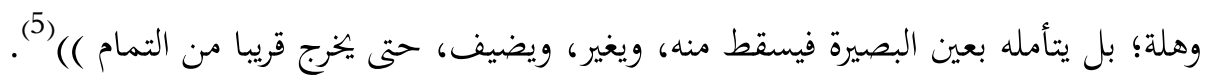

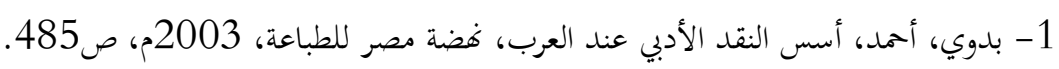

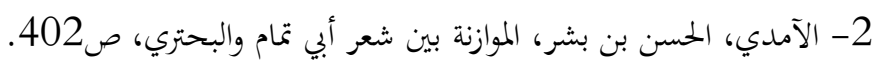

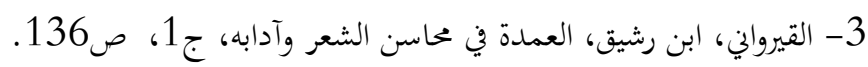

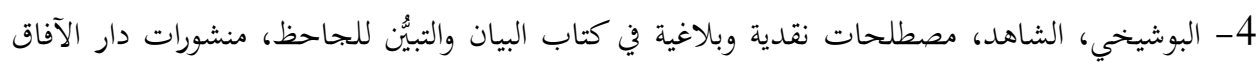

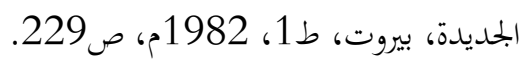
5- العاكوب، عيسى علي، التفكير النقدي عند العرب، مدخحل إلى نظرية الأدب العربي، دار الفكر المعاصر،

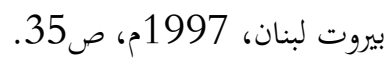


وما كان سبق زهير وابنه كعب والحطيئة، وتفوقهم؛ إلا بسبب تنقيح أشعارهم وتمذيبها

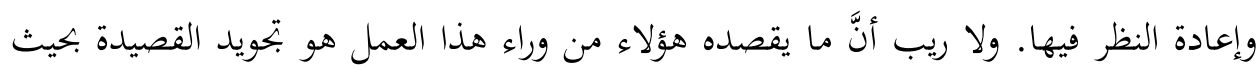
يكون الاهتمام بالألفاظ والمعاني جميعا، وليس لبحرد زخرفتها من الخارج فقط. وقد عدد أبو هلال بعضا من الشعراء الذين يتخذون طريق التهذيب والتنقيح منهجا لهم يقول: (( وكان أبو نواس يعمل القصيدة ويتركها ليلة، ثم ينظر فيها فيلقي أكثرها، ويقتصر على العيون منها فلهذا قصر أكثر قصائده ....، وكان البحتري يلقي من كل قصيدة يعملها

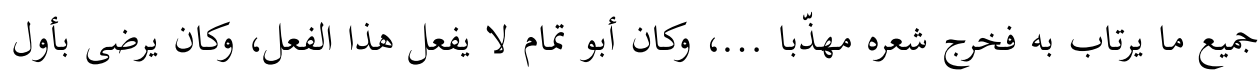

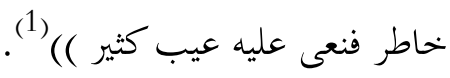
وإذا كان النقاد اختلفوا في تحديد مفهوم الطبع والتكلف؛ فإذهم في الوقت ذاته اختلفوا في تحديد مفهوم الصنعة، إذ جعل بعضهم الصنعة ـ وإن دلت على التنقيح والتهذيب ـ هي التكلف بعينه، ومن ثم، فصلوا الطبع عن الصنعة، وعدُّوا أصحاب الصنعة عبيدا للشعر. وجعل بعضهم الصنعة المتمثلة في مراجعة النص وتنقيحه وتهذيبه، مرحلة أساسية

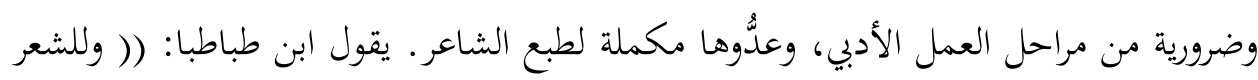
أدوات يجب إعدادها قبل مراسه وتكلف نظمه، فمن تعصَّتْ عليه أداة من أدواته لم يكمل له له ما يتكلفه منه، وبان الخلل فيما نظمه، ولحقته العيوب من كل جهة )( (2).

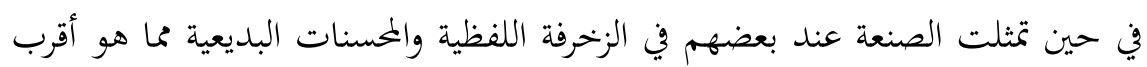

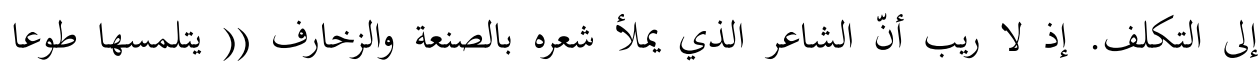

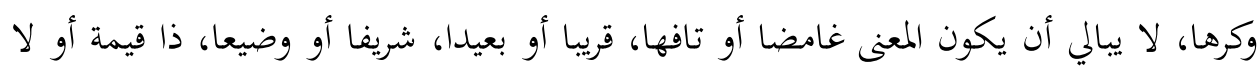

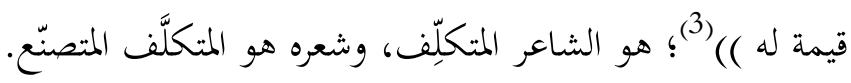

$$
\text { 1- العسكري، أبو هلال، كتاب الصناعتين، ص129. }
$$

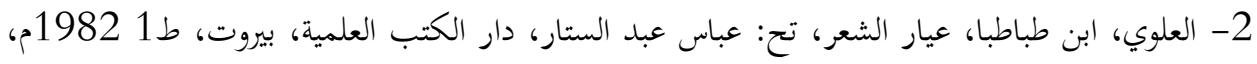


ومن ثنَّة، فالصنعة تكون أقرب إلى الطبع إذا قصد بها تنقيح الشعر وبتويده وإصلاحه،

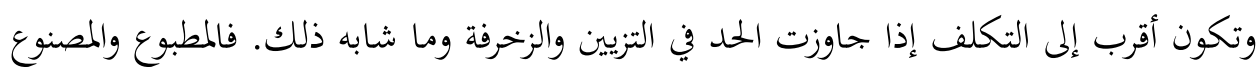

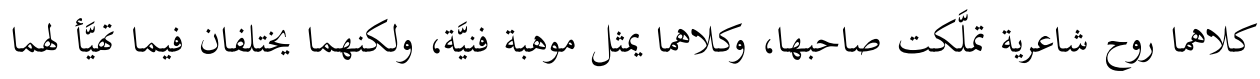

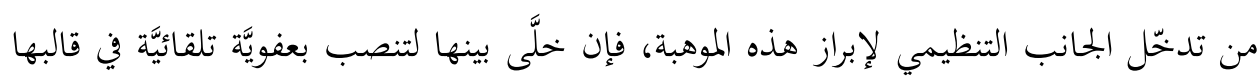

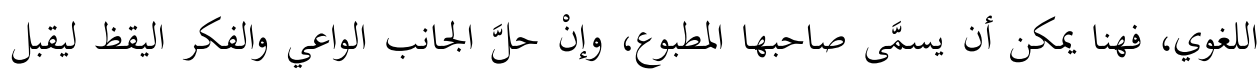
ويرفض واتَّضح طغيان الذهن ليتجاوز المألوف إلى البدعة والإغراب، فهنا يمكن أنس أن يُسمَّى

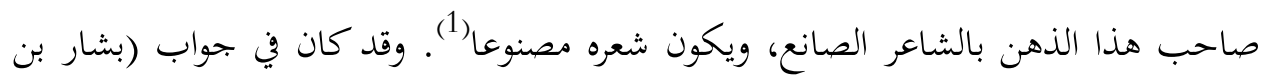
برد) عندما سئل عن سبب تفوقه على أقرانه في إبداع الشعر تحديد لكل من الطبع والصنعة والتكلّف، قال بجيبا: (( لألي لم أقبل كل ما تورده عليَّ قريكتي، ويناجيني به طبعي، ويبعثه

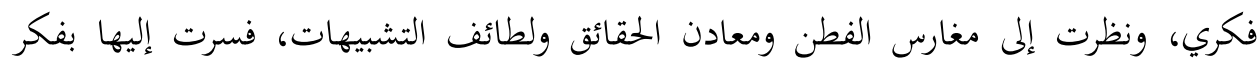

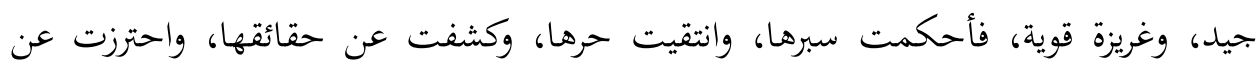

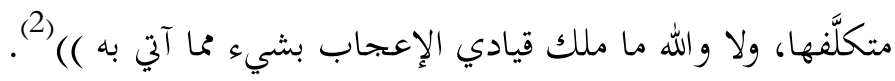
لقد فرق بشار بقوله هذا بين الشعر المطبوع، والشعر المصنوع (المنقح)، والشعر بـاء المتكلّف، وكيف أن الشعر المنقح هو أفضل الأنواع. فالشعر المطبوع عنده ما أوردته القريحة وما ناجاه الطبع. والشعر المنقح هو إحكام المعادن واللطائف والسير إليها بفكر جيد وغريزة قوية. والشعر المتكلَّف هو ما يجب الاحتراز منه والابتعاد عنه. وهذا ما أكده بعض النقاد حين قال: (( والكلام الجيد الطبع مقبول في السمع، قريب المثال، بعيد المنال، أنيق الديباجة، رقيق الزجاجة، يدنو من فهم سامعه كدنوه من وهم صانعه. والمصنوع: مثقف الكعوب، معتدل الأنبوب، يطرد ماء البديع على جنباته، ويجول رونق الحسن في صفحاته كما يجيول السحر في الطرف الكحيل، والأثر في السيف الصقيل. وحمل الصانع شعره على الإكراه في التعمل، وتنقيح المباني دون إصلاح المعاني، يعفي آثار صنعته، ويطفئ أنوار صيغته، ويخرجه إلى فساد التعسُّف، ولئ،

1- ينظر : عيد، رجاء، التراث النقدي (نصوص ودراسة)، منشأة المعارف الإسكندرية، 1990، ص135. 2- القيرواني، ابن رشيق، العمدة في محاسن الشعر وآدابه، 173/2. 
وقبح التكلّف ...، وأحسن ما أجري إليه، وأعول عليه، التوسط بين الحالين، والمنزلة بين المنزلتين من الطبع والصنعة ))(1)، ومن ثم (( فالشعراء ثلاثة، شاعر فطرة، وشاعر صنعة، والثالث الساقط من الحساب شاعر الغفلة، وإذن فالشعر صنوف ثلاثة: شعر الفطرة وهو الأصيل، وشعر الصنعة وهو الدخيل، وشعر الغفلة وهو الطريد الذليل )) (2).

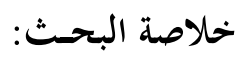
- يعد مصطلح الطبع والتكلّف من أهم المقاييس التي اعتمد عليها النقاد قديما في تقييم القصيدة والشاعر. - يتضح لنا من خلال البحث أن النقاد خلطوا بين بعض المفاهيم من حيث الدلالة،

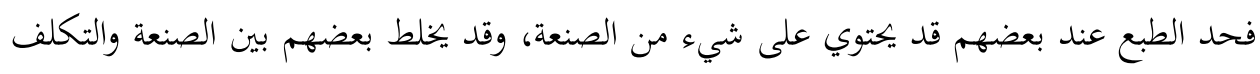

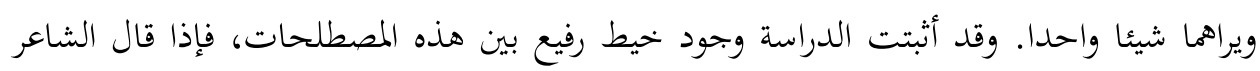

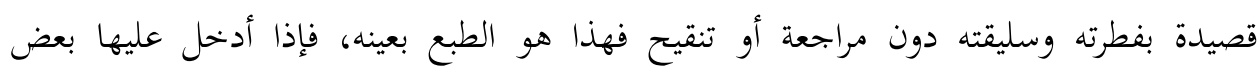
التعديلات فهي الصنعة، فإذا تمادى الشاعر في تعديلاته وأكثر من محسناته وزخحارفه اللفظية فهو

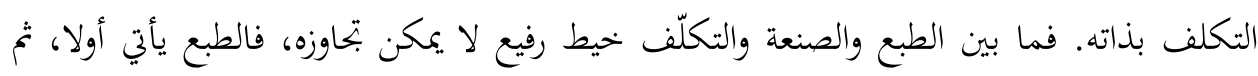

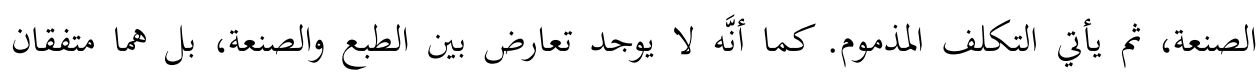

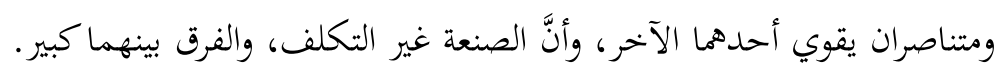

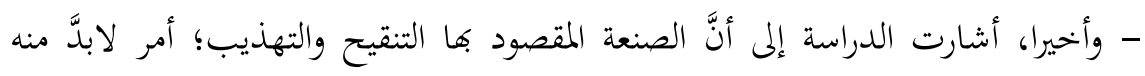

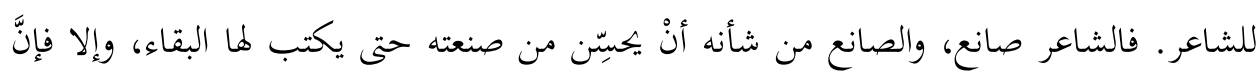

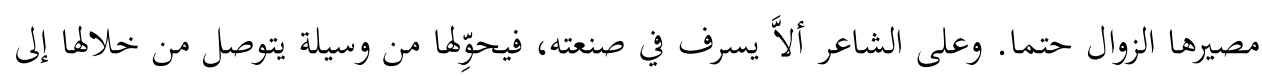

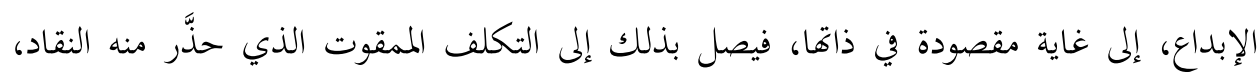
وتحاشاه الفحول من الشعراء.

1- القيرواني، أبو إسحاق إبراهيم بن علي الحصري، زهر الآداب وثمر الألباب، تح: محمد البجاوي، دار إحياء

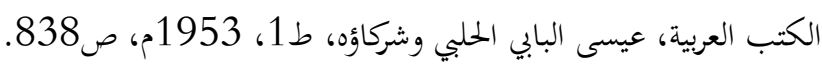

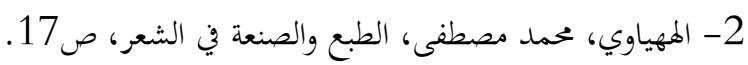




\section{المصادر والمراجع}

1- الآمدي، الحسن بن بشر، الموازنة بين شعر أبي تمام والبحتري، تح: السيد أحمد صقر، دار المعارف، مصر، 1961م. 2- إبراهيم، طه أحمد، تاريخ النقد الأدبي عند العرب من العصر الجاهلي إلى القرن الرابع الهجري، دار

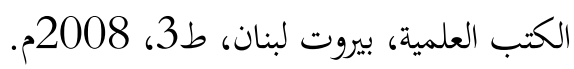

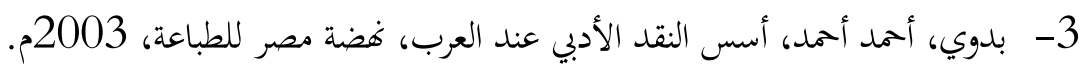

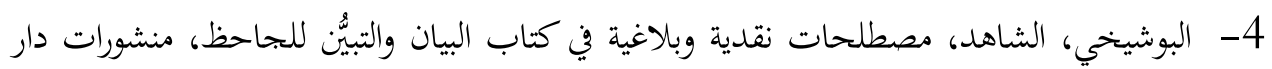
الآفاق الجحديدة، بيروت، ط1، 1982، 1982م. 5- الجاحظ، أبو عثمان، البيان والتبيين، تح: عبد السلام هارون، دار الجيل بيروت، ط2، "د. ت.

6- الجرجاني، عبد العزيز، الوساطة بين المتببي وخصومه، تح: محمد أبو الفضل إبراهيم، علي محمد

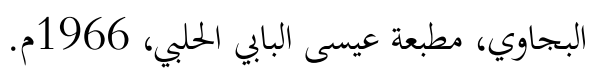

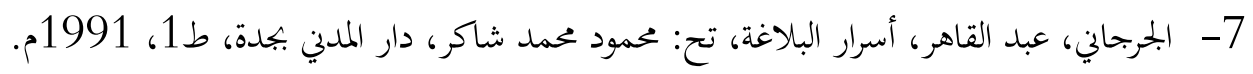

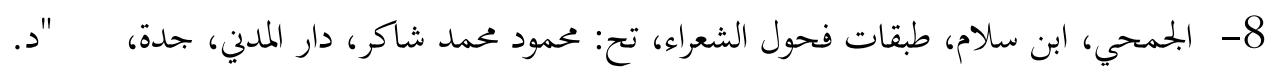
ط، ت ت

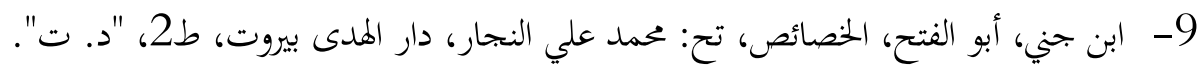

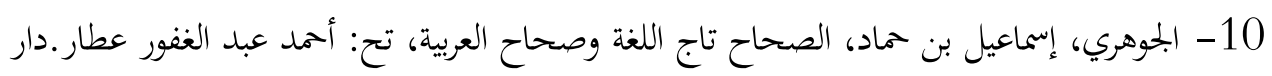

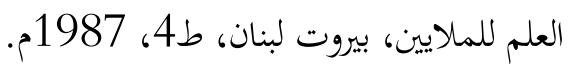

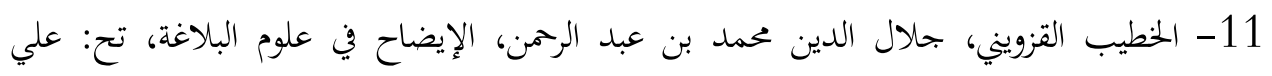

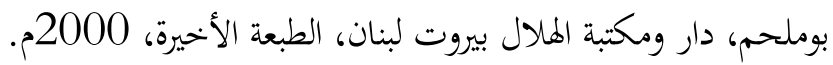

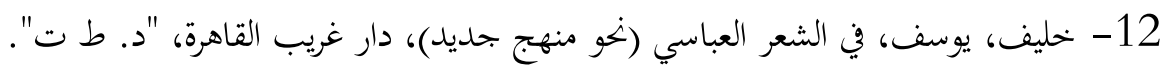

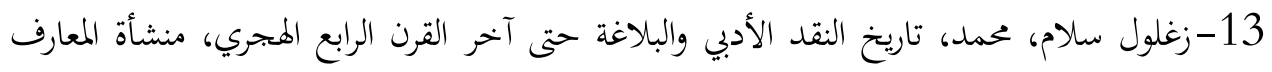

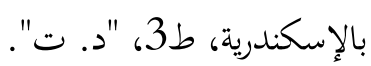
14-الزخشري، جار الله محمود بن عمر، أساس البلاغة، تح: عبد الرحيم محمود، ط1، "د. ت". 
15- ضيف، شوقي، الفن ومذاهبه في الشعر العربي، دار المعارف مصر، ط9، "د. ت". 16- العاكوب، عيسى علي، التفكير النقدي عند العرب، مدخل إلى نظرية الأدب العربي، دار الفكر فئرك المعاصر، بيروت لبنان، 1997م. 17- العسكري، أبو هلال، كتاب الصناعتين (الكتابة والشعر)، تح: مفيد قميحة، دار الكتب العلمية،

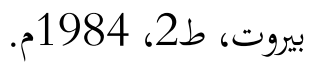
18- العلوي، ابن طباطبا، عيار الشعر، تح:عباس عبد الستار، دار الكتب العلمية، بيروت، ط1 198، 1982 م.

19- عيد، رجاء، التراث النقدي(نصوص ودراسة)، منشأة المعارف الإسكندرية، 1990م.

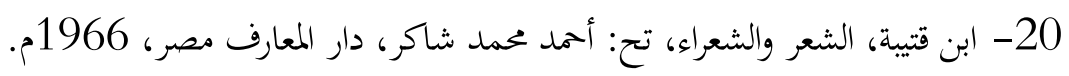

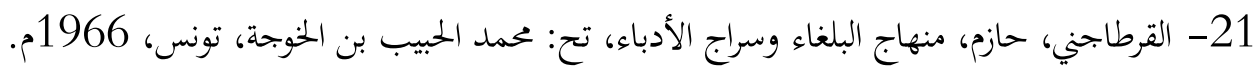

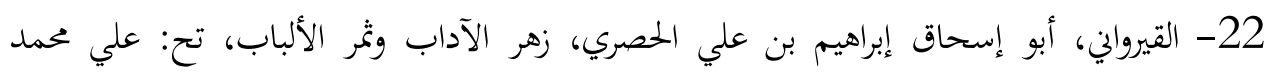

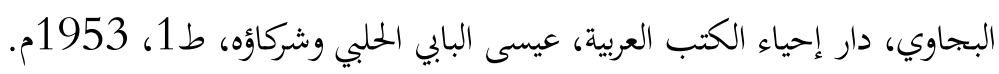

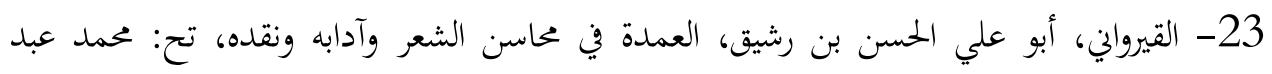

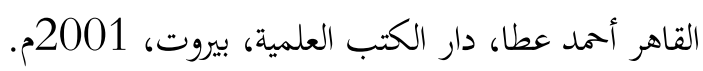

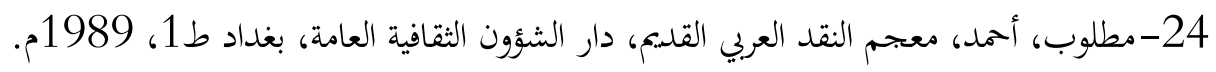

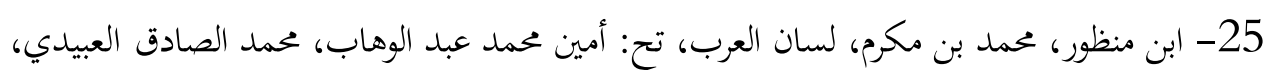

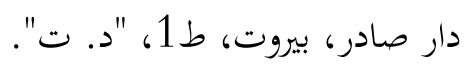
26- هدارة، محمد مصطفى، ابتحاهات الشعر العربي في القرن الثاني الهجري، دار العلوم العربية للطباعة والنشر، ط1، 1988م. 27- الههياوي، محمد مصطفى، الطبع والصنعة في الشعر، مكتبة النهضة المصرية، 1358هـ. 